* Doutora em Direito Constitucional pela Pontifícia Universidade Católica de São Paulo/SP (PUC/SP). Mestra em Direito, pela Instituição Toledo de Ensino em Bauru (ITE). Especialista em Justiça Constitucional pela Universidade de Pisa (Itália). Atualmente é Professora do Curso de Direito do Instituto Municipal de Educação Superior (IMESFAFICA) de Catanduva/SP e da Universidade do Estado de Minas Gerais - Unidade Frutal. E-mail: andreiagarciamartin@ gmail.com. Lattes: http://lattes. cnpq.br/5843968752917552.

** Bacharelando do Curso de Direito da Universidade do Estado de Minas Gerais - UEMG - Unidade Frutal. Bolsista do Programa Institucional de Apoio à Pesquisa $\mathrm{PAPq} / \mathrm{UEMG}$. Monitor do Grupo de Estudos, aprovado pela ABDConst (Academia Brasileira de Direito Constitucional), "IRIS": Igualdade, Reconhecimento e Inclusão Social. E-mail: cesarzacheo@hotmail.com. Lattes: http://lattes.cnpq. br/3506777803570114.

\section{As Pessoas Com Síndrome de Down e As Dificuldades Da Inclusão Educacional No Brasil}

\author{
People With Down Syndrome And The Difficulties Of \\ EDUCATIONAL INCLUSION IN BRAZIL
}

\section{Andréia Garcia Martin * César Augusto Zacheo **}

Como citar: MARTINS, Andréia Garcia; ZACHEO, César Augusto. AS PESSOAS COM SÍNDROME DE DOWN E AS DIFICULDADES DA INCLUSÃO EDUCACIONAL NO BRASIL. Revista do Instituto de Direito Constitucional e Cidadania - IDCC, Londrina, v. 4, n. 2, p 212-229, dez, 2019. ISSN: 2596-0075.

https://doi.org/10.48159/revistadoidcc.v4n2.martin.zacheo

Resumo: Observado o acesso educacional previsto constitucionalmente, o presente estudo se dá na medida em que visa observar como tal direito fundamental social é destinado às pessoas com deficiência no Brasil. Posto isso, tal escopo fará, preliminarmente, algumas delimitações teóricas, buscando evidenciar a diferença entre deficiência mental e intelectual, além de qual se relaciona com a Síndrome de Down. Na sequência, serão verificados os direitos fundamentais que se relacionam com a presente questão, observando os diplomas nacionais e internacionais que viabilizam, ao menos sob o ponto de vista formal, a devida acessibilidade educacional das pessoas com deficiência no país. Diante de tais questões, esta análise utilizará o método de raciocínio dedutivo que sairá das premissas gerais, condizentes à acessibilidade educacional destinada às pessoas com deficiência no Brasil, a fim de se chegar às premissas específicas que demonstrarão a realidade atual, verificando se tais direitos se encontram devidamente garantidos ou não na atual conjuntura educacional. Além disso, a presente pesquisa utilizará também o aparato qualitativo e a fonte bibliográfica, observando tanto as contribuições teóricas na presente questão, bem como sua aplicação na atual conjuntura educacional, promovendo uma educação justa, inclusiva e igualitária capaz de desmitificar preceitos e dogmáticas que discriminam e impedem diariamente o pleno desenvolvimento do grupo em questão.

Palavras-chave: Educação. Pessoas com deficiência intelectual. Legislação. Políticas Públicas. 


\begin{abstract}
Once the educational access planned constitutionally is observed, the present study takes place to the extent that it aims to observe how such a fundamental social right is intended for people with disabilities in Brazil. Having said this, this scope will make, preliminary, some theoretical delimitations, seeking to highlight the difference between mental and intellectual disability, besides which relates to Down Syndrome. Following the fundamental rights relating to this issue will be verified, observing national and international diplomas that make possible, at least from a formal point of view, the proper educational accessibility of persons with disability in the country. Once these questions are observed, this analysis will use the method of deductive reasoning that will come out of the general premises, consistent with educational accessibility aimed at people with disabilities in Brazil, in order to reach the specific premises that demonstrate the current reality, verifying whether or not such rights are properly guaranteed in the current educational environment. In addition, the featured essay will also use the qualitative apparatus and the bibliographic source, observing both the theoretical contributions in this issue, as well as its application in the current educational environment, promoting a fair, inclusive and egalitarian capable of demitting precepts and dogmatics that discriminate and prevent the full development of the group in question on a daily basis.
\end{abstract}

Keywords: Education. People with intellectual disabilities. Legislation. Public Policies. 


\section{INTRODUÇÃO}

Em busca de se discorrer sobre o acesso educacional das pessoas com deficiência intelectual, especificamente as com Síndrome de Down, o presente estudo visa verificar se os dispositivos legais relacionados ao acesso educacional andam sendo cumpridos ou não, evidenciando as dificuldades e as discriminações que acometem diariamente o grupo em questão, além das diversas problemáticas no tocante à inclusão.

À vista disso, inaugura-se a presente pesquisa por meio da conceituação de pessoa com deficiência, bem como procedendo-se à diferenciação terminológica entre os conceitos de pessoas com deficiência mental e intelectual, no afã de promover maior facilitação da compreensão d grupo em questão.

Em seguida, a abordagem recairá sobre a observância das pessoas com Síndrome de Down que fazem parte do grupo condizente às pessoas com deficiência intelectual, especificando as dificuldades no desenvolvimento de tais pessoas, além da relevância da educação para promover o aprimoramento pessoal, além de viabilizar o respectivo bem-estar social inerente a inclusão das pessoas com deficiência no Brasil.

$\mathrm{Na}$ sequência, serão observadas as legislações condizentes ao acesso educacional disciplinado nos dispositivos nacionais e internacionais, especificando os direitos sociais fundamentais relacionados à educação inclusiva destinada às pessoas com deficiência no país, verificando se a atual conjuntura confirma ou não as tutelas em questão.

Por fim, o estudo se direciona à sede conclusiva abordando sobre as dificuldades e as problemáticas relacionadas ao direito ao acesso à educação, verificando o âmbito educacional público e privado, bem como a recente decisão proferida em sede de controle de constitucionalidade através da Ação Direta de Inconstitucionalidade n ${ }^{\circ} 5.357$, afirmando que as instituições mencionadas não poderão se esquivar de garantir a educação inclusiva para todos de forma igualitária sem cobranças adicionais.

Assim sendo, tal abordagem utilizará o método de raciocínio dedutivo, saindo das premissas gerais condizentes à importância da inclusão educacional das pessoas com Síndrome de Down no país, para se chegar as premissas específicas que verificarão como tal acesso tem sido realizado na atual conjuntura educacional, evidenciando as problemáticas existentes e os avanços legais para que se delineie a atual situação institucional. (MEZZAROBA; MONTEIRO, 2016)

Ademais, utilizar-se-á ainda a abordagem qualitativa e a pesquisa bibliográfica para evidenciar as teorias relacionadas com a presente exposição, utilizando-se de livros e artigos científicos para demonstrar a relevância dos instrumentos analisados, além da sua respectiva importância para as pessoas com deficiência e seu acesso educacional no país.

\section{TERMINOLOGIAS, CONCEITO E A DIFERENCIAÇÃO DAS PESSOAS COM DEFICIÊNCIA INTELECTUAL E DEFICIÊNCIA MENTAL NO BRASIL}


Para realizar a análise da distinção dos termos: "deficiência mental" e "deficiência intelectual", inicialmente é imprescindível examinar o novo conceito de pessoa com deficiência advindo com a Convenção Internacional sobre os Direitos das Pessoas com Deficiência, bem como sua regulamentação através da Lei ${ }^{\circ}$ 13.146/15 (Estatuto das Pessoas com Deficiência) haja vista que ambos instrumentos legais acolheram o modelo social e não mais patológico para definir quem são e como são delimitadas as deficiências no país.

Neste sentido, Luiz Alberto David Araujo chama a atenção para que a deficiência seja vista como o "grau de dificuldade para a integração social" (ARAUJO, 2014, p. 8), ou seja, tais dificuldades correspondem a uma forma de delimitar se certas pessoas possuem ou não uma deficiência. Assim, a Convenção Internacional sobre os Direitos da Pessoa com Deficiência elucida que se trata de:

[...] um conceito aberto em que não basta o reconhecimento da existência de um determinado impedimento (alteração da saúde ou estrutura do corpo da pessoa), ou seja, não há um rol de impedimentos aptos a determinarem a inserção de alguém no grupo das pessoas com deficiência, ou ao contrário, sem os quais alguém não poderá ser inserido em tal grupo. (BRASIL, 2009)

À vista disso, insta observar que o referido diploma estabelece em seu artigo $1^{\circ}$ que a conceituação de pessoa com deficiência corresponde diretamente com as diversas dificuldades encontradas no desenvolvimento pessoal dos indivíduos em análise, exemplificando que as pessoas com deficiência são:

[...] aquelas que têm impedimentos de longo prazo de natureza física, mental, intelectual ou sensorial, os quais, em interação com diversas barreiras, podem obstruir sua participação plena e efetiva na sociedade em igualdades de condições com as demais pessoas. (BRASIL, 2009)

Por este conceito, tem-se por necessária a configuração de dois elementos para seu enquadramento, quais sejam: a lesão presente na pessoa, seja ela física, mental, intelectual, e a barreira social que impede tais pessoas de usufruírem dos direitos em condições equivalentes com os demais. Contudo, vislumbra-se que:

[...] o maior problema não é conceituar a pessoa com deficiência, e, sim combater a discriminação que passam diariamente. Enquanto a humanidade não os enxergar como pessoas dignas de direitos e potencialidades, independentemente de sua condição física ou mental, para muitos, os deficientes vão continuar sendo a representação da pessoa (ou coisa) que importuna e é justamente contra esta concepção que o direito deve apoitar sua luta. (MARTIN; MARTA, 2010, p. 260).

Por essas razões, no que diz respeito às pessoas com deficiência intelectual essa discriminação é ainda maior, vez que se encontra encravado no seio social o estigma idealizado da incapacidade, da ausência de autonomia e da falta de liberdade de escolhas daqueles que a detém.

Porém, esses discursos não advêm apenas dos tempos pós-modernos, sendo que no ínterim 
da história diversas foram as formas de tratamento pejorativo destinado às pessoas com deficiência intelectual no Brasil.

À vista disso, insta trazer à baila que em 1961, era utilizada a terminologia "excepcional" presente na Lei das diretrizes e bases da educação em seu capítulo X. Entretanto, em 1971, a mesma lei passou a utilizar "alunos com deficiências físicas ou mentais" ao dispor sobre os tratamentos especiais destinados à educação do grupo em análise.

Posteriormente, o legislador brasileiro, na busca de eliminar termos jocosos e imprecisos do texto Constitucional, trouxe em 1988 a seguinte denominação: "Pessoas Portadoras de Deficiência" (PPD) visando a garantia da erradicação das desigualdades sociais e a possível promoção do bem de todos.

Mais adiante, a título de comparação, cabe citar a instituição do dia 3 de dezembro como o Dia Internacional das Pessoas com Deficiência pela ONU (Resolução 1993/29 de 5 de março de 1993), demonstrando uma pequena variante quanto a denominação brasileira adotada.

Porém, cabe destacar que a Declaração de Montreal sobre Deficiência Intelectual ${ }^{1}$ realizada em 2004 por meio da Organização Pan-Americana da Saúde e Organização Mundial da Saúde, com a participação do Brasil, em Montreal, Canadá, também chamou a atenção para a definição terminológica de pessoas com deficiência. ${ }^{2}$

Nesta esteira, de caráter mais recente, o Estatuto das Pessoas com deficiência, utilizase das "pessoas com deficiência" no tratamento das garantias e efetividades destinadas ao seu público, garantindo assim as recomendações trazidas pela declaração de Montreal, além das diversas Organizações Internacionais, conforme se verifica na sequência:

Incluir a "DEFICIÊNCIA INTELECTUAL" nas suas classificações, programas, áreas de trabalho e iniciativas com relação às "pessoas com deficiências intelectuais" e suas famílias a fim de garantir o pleno exercício de seus direitos e determinar os protocolos e as ações desta área. (MONTREAL, 2004)

No entanto, para analisar as pessoas com deficiência, cabe constatar que, em que pese o senso comum insista em "classificar" indivíduos em "normais" e/ou "anormais", tal diferenciação não possui qualquer relevância quer científica ou prática, pois sendo a deficiência um traço, como qualquer outro, que constitui o ser humano, como uma particularidade que fomenta a singularidade de cada pessoa, devendo, portanto, ser provido o respeito, o reconhecimento e a tutela da diferença e da proibição de discriminações desarrazoadas.

Por outro lado, Smith aponta particularidades nos sistemas de classificação das pessoas

1 Cabe observar que o termo intelectual foi utilizado também em francês e inglês: Déclaration de Montreal sur la Déficiénce Intelectuelle, Montreal Declaration on Intellectual Disability,

2 O termo Deficiência intelectual já havia sido mencionado pela ONU em 1995, quando a Organização das Nações Unidas (juntamente com The National Institute of Child Health and Human Development, The Joseph P. Kennedy, Jr. Foundation, e The 1995 Special Olympics World Games) realizou em Nova York o simpósio chamado INTELLECTUAL DISABILITY: PROGRAMS, POLICIES, AND PLANNING FOR THE FUTURE (Deficiência Intelectual: Programas, Políticas e Planejamento para o Futuro) e por uma organização espanhola que alterou seu nome em 2002 de Confederação Espanhola para Pessoas com Deficiência Mental para Confederação Espanhola para Pessoas com Deficiência Intelectual (Confederación Española de Organizaciones en favor de Personas con Discapacidad Intelectual). (SASSAKI, 2005) 
com deficiência mental, uma vez que:

Trata-se do pensamento tipológico, segundo o qual certos grupos podem ser organizados com base em características compartilhadas, homogêneas, obscurecendo as diferenças individuais. Para o autor, a deficiência mental está sujeita a essa concepção tipológica, como se existisse uma essência da deficiência mental (SMITH, 2002 p. 62).

Desse modo, percebe-se que a deficiência mental se diferencia das concepções estudadas acima, uma vez que contraria a ideia trazida pelo novo conceito de pessoa com deficiência, ao afirmar que as pessoas com deficiência mental só poderão ser analisadas através do diagnóstico clínico.

Eis que, vislumbra-se a proximidade indelével entre deficiência e doença, logo, sob este posicionamento a deficiência deveria ser curada e não compreendida como uma particularidade do ser, haja vista que a doença se oculta nas diversas diferenças individuais. ${ }^{3}$

Contudo, convém ressaltar que a avaliação das deficiências deverá abranger a lesão que cada pessoa traz em si, tanto a questão social, como a sua respectiva inclusão social. Assim, a lesão transcende as características da pessoa na medida em que também compreende um conjunto complexo de condições, que em sua grande maioria surgem no próprio ambiente social diversificado nas diversas formas de preconceito e discriminação.

Por fim, a Associação Americana de Deficiência Intelectual e Desenvolvimento (AAIDD) dispõe que a deficiência intelectual se caracteriza como "limitações significativas tanto no funcionamento intelectual como na conduta adaptativa e está expresso nas habilidades práticas, sociais e conceituais, originando-se antes dos dezoito anos de idade" (AAIDD, 2010, p.31).

Dessa forma, pelas citações transcritas, tornou-se possível observar as diferenças entre as pessoas com deficiência mental e intelectual, além de constatar que a atenção tanto da sociedade quanto do Estado se faz necessária para o pleno desenvolvimento dessas pessoas com deficiência nos diversos meios sociais.

No entanto, o que se nota é um estreitamento de conceitos e definições que se por um lado coopera, e muito, na abordagem educacional e médica de cada indivíduo, ainda não atingiu plenamente o mais importante setor com o qual o tema possui estrita ligação: a sociedade, sendo que:

Especialistas, pesquisadores, reabilitadores, educadores, gestores e pessoas com deficiência têm utilizado modelos de estrutura da deficiência a fim de avançar a implementação dos direitos do segmento populacional em foco. O conceito de estrutura da deficiência reflete o entendimento de que a deficiência tem sido percebida como uma estrutura constituída por fatores do corpo humano, tais como: lesão, perda ou ausência de membros, anomalia, malformação, insuficiência, déficit, disfunção. Por outro lado, estes fatores, por existirem dentro do corpo,

3 Entre os diversos exemplos de deficiência/distúrbio mental, a $11^{\text {a }}$ Classificação Internacional de Doenças (CID) em conjunto com a Organização Mundial da Saúde (OMS) incluirá o "distúrbio de games" como distúrbio mental. Disponível em: https://neurosaber.com.br/vicio-em-games-agora-e-considerado-disturbio-mental-pela-oms/. Acesso em: 20 abr. 2019. 
têm sido frequentemente confundidos como doenças, criando a falsa ideia de que deficiência e doença seriam a mesma coisa. Surgiu daí a histórica atitude da sociedade no sentido de tratar pessoas com deficiência como se elas fossem pessoas doentes pelo simples fato de terem uma deficiência. (SASSAKI, 2012, p. 2)

Ou seja, percebe-se que a desinformação social faz com que o grupo abordado sofra diariamente com diversos preconceitos e discriminações que não observam a sua plena capacidade, além da sua respectiva importância para a manutenção democrática, direcionando ofensas e exclusões simplesmente por não compreenderem tais situações.

Posto isso, tal análise passará a verificar uma ramificação das pessoas com deficiência, afunilando seu foco para as pessoas com Síndrome de Down na busca de delimitar o presente estudo e torná-lo viável para a sua devida aplicação acadêmico-social.

\section{A SÍNDROME DE DOWN ENQUANTO DEFICIÊNCIA INTELECTUAL: NECESSIDADE DE LEGISLAÇÃO E AS MEDIDAS PARA A DEVIDA INCLUSÃo}

Dentro das diversas deficiências intelectuais encontradas na atualidade, a Síndrome de Down é um bom exemplo na representação dessas pessoas, haja vista que tal Síndrome, causada pela trissomia do cromossomo 21, traz diversas características físicas relacionadas com o comprometimento intelectual de forma variável entre seus indivíduos.

Assim, por se tratar de uma das Síndromes mais conhecida e pesquisada na contemporaneidade, o presente ensaio visa abordar a referida temática na busca de garantir uma maior amplitude quanto à questão, visando tecer análises sobre os direitos fundamentais presentes na legislação pátria destinada à garantia do direito à educação inclusiva das pessoas com Síndrome de Down.

Nesse sentido, Maria Antonieta M. A. Voivodic traça sobre a educação inclusiva como um ganho social advindo através de muita luta dos diversos movimentos que almejam promover o desenvolvimento educacional do grupo em evidência, assim, a autora afirma que: "Quando falamos em inclusão, é importante assinalar que não estamos nos referindo a um modismo, ou apenas à tendência mais recente na educação. A educação inclusiva não surgiu por acaso. É fruto de um momento histórico e faz parte de um sistema social e econômico em transformação" (VOIVODIC, 2011).

O caráter principal do direito à inclusão educacional está ligado diretamente à participação da pessoa com Síndrome de Down nas diversas searas de sua vida, devendo poder usufruir de todas as oportunidades, dentre elas a educacional, na busca de se desenvolver plenamente com as demais pessoas através de um processo inclusivo gradual.

Nesta linha, Rosita Edler Carvalho, ao abordar sobre o direito à inclusão, traz o seguinte posicionamento acerca da necessidade da inclusão no próprio âmbito educacional, afirmando que: “Assim como a integração, a inclusão é um processo que não vai ocorrer por decreto dos 
legisladores! E mais, essa inclusão, cujo corolário é a integração, só terá os efeitos desejados se, e apenas se, for aceita por toda a comunidade escolar" (CARVALHO, 2004). ${ }^{4}$

À vista disso, apesar de constitucionalmente estar garantido o direito à inclusão, torna-se evidente destacar que a atual conjuntura social demonstra uma comunidade que ainda continua dificultando essa inclusão, especialmente em aceitar e respeitar as diferenças que são ínsitas às pessoas com Síndrome de Down.

Ademais, um dos principais prejuízos, tanto para a sociedade, como para essas pessoas, está no fato de que se bem estimulados, valorizados e principalmente, com seus direitos reconhecidos efetivados, terão plena condição de trabalhar e estudar como qualquer outra pessoa.

Valendo-Se dessa linha de pensamento, a Declaração de Montreal sobre a deficiência Intelectual (2004) traz a necessidade de legislações específicas para o tratamento e os direitos das pessoas com deficiência no país, buscando a igualdade material, a dignidade da pessoa humana e os direitos dessas pessoas garantidos através da obrigação do Estado na garantia de inclusão a todos, conforme se vislumbra a seguir:

B. Cumprir as obrigações estabelecidas por leis nacionais e internacionais criadas para reconhecer e proteger os direitos das pessoas com deficiências intelectuais. Assegurar sua participação na elaboração e avaliação de políticas públicas, leis e planos que lhe digam respeito. Garantir os recursos econômicos e administrativos necessários para o cumprimento efetivo destas leis e ações;

C. Desenvolver, estabelecer e tomar as medidas legislativas, jurídicas, administrativas e educativas, necessárias para realizar a inclusão física e social destas pessoas com deficiências intelectuais;

D. Prover as comunidades e as pessoas com deficiências intelectuais e suas famílias o apoio necessário para o exercício pleno destes direitos, promovendo e fortalecendo suas organizações;

E. Desenvolver e implementar cursos de formação sobre Direitos Humanos, com treinamento e programas de informação dirigidos a pessoas com deficiências intelectuais. [...] (MONTREAL, 2004.)

Todos os elementos em destaque apontam para uma necessidade tanto social, quanto governamental de cuidado e atenção no tratamento das pessoas com deficiência intelectual, garantindo suas características como cidadãos sem desrespeitar suas necessidades específicas.

Com a Síndrome de Down não seria diferente, vez que para alguns estudiosos a parte do atraso ou da falta de desenvolvimento intelectual de algumas pessoas se dá principalmente pelo ambiente de reclusão e abandono que são diariamente submetidos, especificamente nos primeiros anos de sua vida, momentos esses essenciais para o progresso de seu desenvolvimento. (PENA, 2009.)

Para tanto, é possível vislumbrar a necessidade de medidas efetivas quanto ao direito à

4 Cabe ressaltar que a terminologia "integração" e "inclusão" são diferenciadas por diversos doutrinadores, trazendo o entendimento de que a integração, diferente da inclusão, diz respeito ao trabalho individualizado feito pela instituição de ensino com as pessoas com deficiência, no entanto, a inclusão, na linha contrária, versa sobre o atendimento das necessidades da criança e os meios de incluí-la na sala de aula, visando à presença da diversidade no mesmo ambiente. 
inclusão, visto que o abandono e a segregação das pessoas com Síndrome de Down trazem danos irreversíveis a essas pessoas, haja vista que o estímulo motivado nos primeiros anos de vida é essencial na formação e no devido aprendizado dessas pessoas.

No entanto, como serão garantidos esses direitos se não houver a efetiva inclusão do indivíduo tanto na escola, quanto no próprio convívio social?

Perante essa problemática, a Constituição da República Federativa do Brasil ${ }^{5}$ trouxe normatizado o dever do Estado, da família e da sociedade no tocante ao direito do acesso educacional destinado a todos. Porém, o que esperar em situações nas quais as famílias não podem arcar com despesas extras como o acompanhamento de profissionais treinados para esse fim?

Ante essa questão, torna-se relevante destacar que hoje, em grande parte, no caso da Síndrome de Down a população carente pode contar apenas com as APAE's ou outros tipos de associações que prestam auxílio a essas pessoas e que nem sempre ocorre em todas as cidades, o que segundo Gil Pena não é suficientemente para a devida inclusão do grupo em questão, conforme se verifica a seguir:

Hoje, reconhece-se que as pessoas com Síndrome de Down necessitam ser estimuladas, para que se desenvolvam. Há programas de fisioterapia, terapia ocupacional e fonoaudiologia orientados a oferecer um reforço na aquisição de habilidades específicas, em geral motoras. Com isso, conseguem alcançar mais precocemente os marcos do desenvolvimento motor, como sentar e andar. $\mathrm{O}$ estímulo tem de ser oferecido também como reforço ao seu desenvolvimento cognitivo. Esse reforço são as ferramentas da cultura, que podem compensar a deficiência. Para que possam de fato aprender, contudo, necessitamos mudar nossa atitude em relação a essas pessoas. Mudar de atitude significa reconhecer e confiar em sua capacidade de superar as dificuldades. Significa entender que é na interação social que se origina o desenvolvimento. Temos de nos comprometer a oferecer um contexto que estimule esse desenvolvimento. (PENA, 2009.)

Nesse contexto, a busca pelo desenvolvimento das pessoas com deficiência deve ser pautada principalmente nas políticas públicas que se direcionam a trazer o caráter efetivo no tocante aos direitos básicos resguardados pelo princípio da igualdade presente no artigo $5^{\circ}$ da Carta Magna brasileira, fazendo com que a inclusão ocorra como característica essencial e fundamental na formação das pessoas com deficiência, oferecendo locais e profissionais adequados para tratarem da melhor forma possível os estímulos dos mesmos, garantindo, assim, a verdadeira efetividade do direito à inclusão das pessoas com Síndrome de Down na educação.

Chegado a esse momento, o presente estudo se destinará a abarcar sobre os avanços e as necessidades da efetivação dos direitos fundamentais sociais condizentes à educação, verificando os passos dados pela República brasileira e a carência de novas regulamentações.

5 Visto o poder Constitucional frente ao dever do Estado, da família e da sociedade no acesso à educação, o Estatuto da Criança e do Adolescente (ECA) dispõe sobre o dever Estatal na garantia do atendimento educacional especializado aos portadores de deficiência. Posterior, o Estatuto das Pessoas com Deficiência também trouxe o dever do Estado, mas cumulado com a família e a sociedade no tocante ao direito do acesso à educação. 


\section{LEGISLAÇÃO ACERCA DO ACESSO À EDUCAÇÃO: DIREITOS OU CONFIRMAÇÃO DA EXCLUSÃO?}

Os Direitos Humanos em suas principais dimensões: liberdade, igualdade e fraternidade, visou acompanhar e garantir à sociedade os direitos das minorias e o clamor humanitário frente as suas necessidades básicas. Assim, a representação das minorias carecedoras da proteção do Estado e da justiça começou a acontecer nas diversas searas, garantindo, dessa forma, o direito reivindicado pelas classes minoritárias. Assim, a Declaração Universal dos Direitos Humanos trata que:

A educação deve visar à plena expansão da personalidade humana e ao reforço dos direitos humanos e das liberdades fundamentais e deve favorecer a compreensão, a tolerância e a amizade entre todas as nações e de todos os grupos raciais ou religiosos, bem como o desenvolvimento das atividades das Nações Unidas para a manutenção da paz. (DUDH, 1948)

Ao trazer a presente firmação para o contexto atual, pode-se analisar que na maioria das vezes os direitos existem, porém, não são efetivos de fato na sociedade. Nesse sentido, o autor Norberto Bobbio discorre sobre as primeiras dimensões dos direitos humanos e a problemática da eficácia da norma na sociedade:

Mas os direitos de que fala a primeira são somente os proclamados nas instituições internacionais e nos congressos, enquanto os direitos de que fala a segunda são aqueles que a esmagadora maioria da humanidade não possui de fato (ainda que sejam solene e repetidamente proclamados). (BOBBIO, 1992, p. 10.)

Neste liame, visto que a Educação é ligada à noção de direitos humanos e mais especificamente ao princípio da igualdade, frente ao exposto, cabe ressaltar a relevância dessa afirmação ante aos inúmeros Tratados e Constituições que tem o caráter de assumir os direitos que outrora foram negados, seja por períodos políticos conturbados ou simplesmente pela falta de legislação.

Porém, mesmo abordados e garantidos na norma, tais direitos não são efetivos na sociedade, caindo no vazio e na descrença popular e carecendo, nessas razões, da sua devida efetivação.

Dessa forma, o ordenamento jurídico brasileiro, ao abordar sobre o direito ao acesso à educação, trouxe desde 1961 a possibilidade do atendimento aos "excepcionais" ${ }^{6}$ na Lei das diretrizes e bases da educação do Ministério da Educação (MEC), tal legislação previu ainda a doação de bolsas, empréstimos e subvenções a escolas particulares que oferecem ensino eficiente aos excepcionais, complementando a mesma lei em 1971 e 1996 para que as pessoas com deficiência recebessem tratamento especial e a flexibilidade respectivamente na educação.

6 Termo utilizado à época. 
Para determinar as diretrizes básicas da educação especial em nível nacional foi criado, em 1973, o Centro Nacional de Educação Especial (CENESP), que ganhou força durante esses anos e, em 1987, foi transformado em Secretaria de Educação Especial (SESP), com sede em Brasília.

Nesse sentido, a Constituição da República Federativa do Brasil de 1988, ao tratar sobre os direitos sociais, dispôs em seu artigo $6^{\circ}$ a educação como direito fundamental de todos, abordando posteriormente no artigo 205 e 206 o direito igualitário do acesso à educação, sendo dever a ser garantido pelo Estado, família, em conjunto com a sociedade na busca de uma educação com base igualitária, livre, plural, gratuita, democrática e que vise à qualidade para todos.

Também em 1988, a Convenção Americana sobre Direitos Humanos em matéria de direitos econômicos, sociais e culturais (protocolo de São Salvador), introduziu ao sistema jurídico brasileiro, pelo Decreto $\mathrm{n}^{\mathrm{o}} 3.321 / 1999$, que programas de ensino diferenciados deveriam ser destinados às pessoas com deficiência, a fim formar essas pessoas e auxiliá-las na sua necessária inclusão.

Isso posto, observa-se que o direito à educação também fora confirmado mais tarde pelo Estatuto da Criança e do Adolescente de 1990 (ECA) a fim de garantir o livre acesso à educação e o dever do Estado perante a efetividade do mesmo direito social fundamental.

Para a maioria dos autores, no âmbito da legislação aplicável as pessoas com deficiência, em se tratando de inclusão, a Declaração de Salamanca (1994) e o Plano de Ação para a Educação de Necessidades Especiais (2010) são os mais completos textos sobre a inclusão na educação.

Aliás, o que se destaca nesses documentos é o fato de colocar a inclusão como medida educativa para as pessoas com deficiência em geral, e não somente aquelas pessoas com determinadas necessidades específicas, por exemplo; o que eleva tal medida a uma necessidade essencial para qualquer modalidade ou restrição intelectual.

Ademais, a Declaração de Salamanca, aprovada em julho de 1994, versou sobre princípios basilares, além de políticas e práticas em educação especial, afirmando que algumas obrigações às entidades escolares que não poderão se olvidar de possibilitar o devido acesso educacional das pessoas com deficiência, conforme se demonstra na sequência:

Todas as escolas deveriam acomodar todas as crianças independentemente de suas condições físicas, intelectuais, sociais, emocionais, linguísticas e outras. Deveriam incluir crianças deficientes e superdotadas, crianças de rua e que trabalham, crianças de origem remota ou de população nômade, crianças pertencentes à minoria linguísticas, étnicas ou culturais e crianças de outros grupos em desvantagem ou marginalizadas... No contexto destas Linhas de Ação o termo 'necessidades educacionais especiais' se refere a todas aquelas crianças ou jovens cujas necessidades se originam em função de deficiências ou dificuldades de aprendizagem e têm, portanto, necessidades educativas especiais em algum momento de sua escolarização. As escolas têm que encontrar a maneira de educar com êxito todas as crianças, inclusive as que têm deficiências graves (SALAMANCA, 1994) 
Ao retornar nas Convenções Internacionais, a Convenção de Nova York (2007) sobre os direitos das pessoas com deficiência tratou sobre o direito à educação a fim de efetivar, sem discriminação e com igualdade, a educação inclusiva de qualidade para todos.

Por fim, e mais destinado à temática desta pesquisa, o Estatuto das Pessoas com Deficiência (2015) destinou capítulo específico para tratar sobre o acesso à educação, trazendo novamente o dever do Estado em prestar tal direito, bem como atribuição da família e da sociedade na garantia de uma educação inclusiva de qualidade a todos.

Dessa forma, nota-se que o princípio da igualdade pertinente às normas jurídicas abordadas evidencia tratamento equânime destinado às pessoas com deficiência e a inclusão educacional como garantia e direito de todos. Entretanto, necessário se faz, portanto, que se celebrem algumas conquistas!

Neste sentido, o cenário legislativo em face das pessoas com deficiência no Brasil passou de um caráter parcelar, seja assistencial e previdenciário, direcionando-se a contemplar outras medidas de grande relevância para a garantia de todos os direitos e da autonomia das pessoas com deficiência, especialmente quanto às previsões legais no âmbito educacional.

Além disso, tal alteração acompanhou sem dúvida as mudanças de percepção do tema da deficiência em todo mundo, em especial, por organismos como a $\mathrm{ONU}^{7}$; a Organização Mundial de Saúde e por outras organizações de âmbito mundial ${ }^{8}$.

Mas a existência de legislação pertinente não para por aí. Segundo Vera Lúcia Flor Sénéchal de Goffredo9:

O Princípio $5^{\circ}$ da Declaração dos Direitos da Criança garante à pessoa portadora de deficiência o recebimento de educação, tratamento e cuidados especiais. No mesmo sentido, a Constituição Brasileira de 1988 garante aos portadores de deficiência "atendimento educacional especializado, preferencialmente na rede regular de ensino" (Art. 208, III). Este direito, também, é reiterado no Art. 54, III, do Estatuto da Criança e do Adolescente (Lei no 8.069, de 13 de julho de 1990). Da mesma forma, o Plano Decenal de Educação para Todos (MEC - 1993/2003), em seu capítulo II, C, ação 7-, prevê a integração à escola de crianças e jovens portadores de deficiência.

Já a nova Lei de Diretrizes e Bases da Educação (Lei $n^{0}$ 9.394/96) apresenta características básicas de flexibilidade, além de algumas inovações que em muito favorecem o aluno portador de necessidades educativas especiais. Pela primeira vez surge em uma LDB um capítulo (Cap. V) destinado à Educação Especial, cujos detalhamentos são fundamentais: garantia de matrículas para portadores de necessidades especiais, preferencialmente na rede regular de ensino (Art. 58); criação de serviços de apoio especializado, para atender às peculiaridades

7 Podem ser destacados os documentos da ONU: Programa de Ação Mundial para Pessoas com Deficiência Aprovado na Assembleia Geral das Nações Unidas em dezembro de 1982, e as chamadas Normas Uniformes sobre a Linguagem de Oportunidades para a Pessoa Portadora de Deficiência (Resolução nº 48/96 de 20 de dezembro de 1993).

8 Tais como: Declaração Mundial sobre Educação para Todos aprovada na Conferência Mundial sobre Educação para Todos: Satisfação das Necessidades Básicas de Aprendizagem, ocorrida em Jomtien, Tailândia, em março de 1990, e Declaração de Salamanca de Princípios, Política e Prática para as Necessidades Educativas Especiais, elaborada em decorrência da Conferência Mundial sobre Necessidades Educacionais Especiais: Acesso e Qualidade, promovida 9 pelo governo da Espanha e pela Unesco em junho de 1994. 
da clientela de Educação Especial (Art. 58, $\S 1^{\circ}$ ); oferta de Educação Especial durante a educação infantil (Art. 58, § $3^{\circ}$ ); especialização de professores (Art. 59, III). Muito importante, também, é o compromisso do poder público de ampliar o atendimento aos educandos com necessidades especiais na própria rede pública e de ensino (Art. 60, parágrafo único). (GODOFFREDO, 1999, p. 29)

Dessa forma, pode-se afirmar que assim como a sociedade foi a mola propulsora para a conquista de vários direitos sociais, ainda se está distante de projetar os mesmos ganhos com relação aos direitos das pessoas com deficiência intelectual, já que possuem, até hoje, um forte preconceito e despreparo por parte dos profissionais na área da educação em lidar com essas questões.

Neste ínterim, a proposta legislativa e da maioria dos educadores de apresentar, principalmente a escola pública como um ambiente democrático e de inclusão, esbarra em circunstâncias práticas como a necessidade de adaptação física (em alguns casos) do ambiente escolar e sem dúvida da capacitação dos profissionais da educação que se complica ainda mais com a necessidade de liberação de verbas para a educação e para projetos especiais como esse.

Com certeza, sem o estímulo e a necessidade da sociedade em ver o direito dessas minorias resguardado, o Estado não parece pretender cumprir seu papel a contento.

Ademais, o que não se deve olvidar é que mesmo em face das pessoas com Síndrome de Down há diversos nuances de aprendizagem, devido a heterogeneidade que o grupo é dotado, devendo, nesse sentido, se estabelecer um currículo aberto que instigue novas habilidades e competências dessas pessoas, visando seu pleno desenvolvimento que fomente sua autonomia e cidadania para posterior inclusão, seja educacional ou no próprio mercado de trabalho.

Assim, sendo o direito à inclusão social e educacional pressuposto do direito à igualdade da pessoa com deficiência, é o princípio regente dos direitos fundamentais de segunda geração, compostos dos direitos sociais, culturais e econômicos que visam trazer proteção para todos, independentemente das suas respectivas situações.

Posto isso, considerando que a inclusão das pessoas com deficiência visa à preservação da igualdade, consequentemente, o direito à inclusão social dessas pessoas também integra a segunda dimensão dos direitos fundamentais, conforme dispõe Vera Lúcia Flor Sénéchal de Godoffredo:

Como já vimos anteriormente, o movimento pela sociedade inclusiva é internacional, e o Brasil está engajado nele, o que é no mínimo apropriado, já que temos cerca de 15 milhões de deficientes segundo a Organização das Nações Unidas (ONU), cuja grande maioria está, provavelmente, aguardando a oportunidade de participar da vida em sociedade, como é seu direito. Assim, necessitamos de uma nova escola que aprenda a refletir criticamente e a pesquisar. Uma escola que não tenha medo de se arriscar, com coragem suficiente para criar e questionar o que está estabelecido, em busca de rumos inovadores, e em resposta às necessidades de inclusão. (GODOFFREDO, 1999, p. 45-46)

Desse modo, fica expresso a necessidade de políticas públicas principalmente no tocante 
ao acesso à educação das pessoas com deficiência, sendo assim, o Estado é o principal órgão na garantia da inclusão diante das diversas searas sociais, principalmente na educação que é instrumento fundamental para as pessoas com deficiência, destacando as com Síndrome de Down que necessitam de estímulos especiais para o seu pleno desenvolvimento humano/social. Para isso, o Brasil já deu seus primeiros passos, mas ainda há muito para se lutar.

\section{AS DIFICULDADES E A PROBLEMÁTICA DO DIREITO AO ACESSO À EDUCAÇÃO NO BRASIL}

Dentre os diversos direitos das pessoas com deficiência, o direito à inclusão, exposto na legislação pátria e internacional, dispõe que toda pessoa com deficiência intelectual, inclusive as com Síndrome de Down, tem o direito de ser matriculado e cursar uma rede de ensino regular. Ademais, observa-se ainda que o não cumprimento dessa lei deve ser denunciado às autoridades (Conselho Tutelar e Ministério Público Estadual) para que as medidas punitivas sejam adotadas.

Nessa perspectiva, cabe à sociedade, à família e à escola fazerem cumprir seus direitos e deveres garantidos constitucionalmente. Werneck, membro do Down Syndrome Medical Interest Group, afirma que:

Partindo da opinião de que quanto mais a criança interage espontaneamente com situações diferentes mais ela adquire conhecimentos, fica fácil entender porque a segregação é prejudicial tanto para os alunos com Necessidades Especiais como para os "normais", isto porque ela impede que as crianças das classes regulares tenham oportunidade de conhecer a vida humana com suas dimensões e seus desafios. (WERNECK, 1997, p.15)

Assim, conforme expresso pela autora, a sociedade deve analisar que a inclusão gera benefícios para ambos os lados, tanto para a criança com necessidades especiais quanto para as demais pessoas que, através dessa inclusão, passam a conviver conhecendo o quão grande é a diversidade e a pluralidade dessas pessoas na vida social.

Nesse sentido, percebe-se que a inclusão realizada de modo correto só traz benefícios a todos participantes, fazendo com que as crianças recepcionem o tema e dessa forma incluam o deficiente em seu meio educacional, possibilitando, por outro lado, uma percepção sensorial e cognitiva mais avançada e consequentemente uma melhora no processo de desenvolvimento intelectual e na aprendizagem dessas pessoas.

Ainda com relação ao sistema público de ensino, o Governo Federal presta apoio técnico e financeiro para a implantação das salas multifuncionais de recursos nas escolas públicas (Programa de Implantação das Salas de Recursos Multifuncionais); para a capacitação dos professores, gestores e demais profissionais da educação (Programa Educação Inclusiva e para adequação arquitetônica dos prédios escolares (Programa Escola Acessível)).

É possível analisar que no caso da Síndrome de Down a inclusão já tem sido difundida a 
ponto de não ser indicado nesse caso o chamado Atendimento Educacional Especializado (AEE) previsto no artigo 208, III, da Constituição Republicana, muito indicado para casos em que as pessoas com deficiência apresentam dificuldades de interação com o grupo, como no caso do espectro autista.

Concomitantemente, ressalta-se ainda que no caso da Síndrome de Down as famílias têm procurado esse apoio extra nas APAE's ou com profissionais particulares, já no caso de síndromes menos difundidas (estudadas) e principalmente em cidades com menos recursos em que muitos indivíduos não têm qualquer acesso educacional, as APAE's têm se dado através de uma ajuda paliativa, mas não imiscuindo o devido dever Estatal.

Nesse sentido, a autora Erenice Natália S. Carvalho vem afirmar que a educação não se baseia apenas na adequação curricular, porém nas mudanças do ambiente escolar a fim de criar um ambiente que as pessoas com deficiência se sintam incluídas e não o inverso, veja:

No Brasil, os procedimentos de adaptações curriculares estão respaldados pela Lei no 9.394, de Diretrizes e Bases da Educação Nacional (Cap. V, Art. 59). A educação inclusiva, entretanto, não se esgota na observância da lei, que a reconhece e garante, mas requer uma mudança de postura, de percepção e de concepção dos sistemas educacionais. As modificações necessárias devem abranger atitudes, perspectivas, organização e ações de operacionalização do trabalho educacional. (CARVALHO, 1999. p. 45-46)

Outro elemento que deve ser desmistificado é a ideia de que a rede pública não recebe alunos com deficiência somente por ausência de recursos, haja vista que o Estado é devedor das obrigações positivas em favor dos seus cidadãos, em especial à criança e ao adolescente, deveres esses que serão alcançados mediante a vigência efetiva de políticas públicas capazes de materializar aos seus beneficiários a efetiva fruição dos direitos previstos em lei, há exemplo do ensino fundamental obrigatório.

Desse modo, cabe ao judiciário intervir quando o fato ocorrer e fazer com que as obrigações do Estado sejam realizadas com eficácia direta e imediata, devendo analisar principalmente as políticas públicas relacionadas à temática e a violação do direito da pessoa.

Nesse sentido, o Supremo Tribunal Federal dispôs que as políticas públicas não devem se submeter à insuficiência orçamentária (princípio da reserva do possível) na busca de efetivar a dignidade da pessoa humana e principalmente o direito ao acesso à educação.

Apesar de sua característica privada, as instituições particulares de ensino também têm obrigação de cumprir as mesmas normas no tocante a matrícula dos alunos com deficiência, qualquer que seja a deficiência, bem como a adaptação dos currículos dos professores e dos seus ambientes físicos, atitudinais e de tecnologias assistivas.

Neste caso, o Supremo Tribunal Federal, em sede de Ação Direta de Inconstitucionalidade $\mathrm{n}^{\circ}$ 5.357, determinou a preservação do direito antidiscriminatório, proibindo qualquer cobrança extra que viole a igualdade entre os alunos, fomentando, nessas razões, o mandamento constitucional da proibição das diversas modalidades de discriminação. 
Por outro lado, o simbolismo constitucional contribui em muito na falta da efetividade do direito ao acesso à educação no Brasil, haja vista que conforme expresso nas disposições acima, o país possui grande quantidade normativa referente à temática.

Porém, devido à falta de conhecimento pelos diversos setores sociais e até mesmo das próprias pessoas com deficiência e de seus familiares, a norma recai sobre o esquecimento público, visto que apenas alguns setores detém o conhecimento normativo, tais como: as famílias, uma parcela especializada de educadores e profissionais da área médica e poucos legisladores/ doutrinadores.

Posto isso, falta, no entanto, que cada um desses setores exija um maior cumprimento das normas já existentes, mas, principalmente, urge-se por um clamor social pela igualdade de direitos de todos os indivíduos, sem que sejam realizadas quaisquer formas de discriminação, especificamente quando se lida com as pessoas com deficiência e as pessoas com Síndrome de Down existentes no país.

Sem pressão social, tais direitos estão fadados ao desrespeito e ao esquecimento, e, quiçá, o desuso. No entanto, o Brasil encontra-se num momento de necessidade de ações concretas e não mais de normatização.

Aliás, entes do Estado brasileiro, por sua vez, principalmente por meio dos órgãos e agentes públicos, tem o dever de efetivar as políticas de ações afirmativas constantes nos planos de educação especial e inclusão para as pessoas com deficiência, sem delegá-las ao terceiro setor para lidar com tais situações.

Ou seja, uma sociedade que não respeita as diferenças entre seus indivíduos é pobre, sem vida e tendenciosa, haja vista que se não houver maior direcionamento em direção à inclusão haverá perdas irremediáveis sobre as riquezas que a diversidade que cada ser humano carrega em si, tendenciosamente ter-se-á uma sociedade fadada a aproximar-se a uma linha de produção, focada na ideia de igualdade meramente formal e não aceitação e respeito à diferença.

Por tudo isso, não se pode somente estabelecer parâmetros fundados na homogeneidade da sociedade, pois uma sociedade que se nomina por democrática e pautada em valores como a igualdade, tornam-se prementes meios adequados, como a educação, para a garantia de que todos possam usufruir de um desenvolvimento pleno e digno e que traga efetividade na formação de todos, principalmente quanto às pessoas com deficiência existentes no país.

\section{CONSIDERAÇÕES FINAIS}

Visto que o acesso à educação é direito de todos, o presente artigo analisou a realidade das pessoas com deficiência intelectual na busca por uma educação igualitária, inclusiva e de qualidade, sendo possível concluir que principalmente no caso das pessoas com Síndrome de Down, a educação é característica fundamental para o seu pleno desenvolvimento pessoal e autonomia existencial e social.

No entanto, essa educação deve ocorrer sobre determinados moldes que influenciarão na 
aprendizagem eficaz dessas pessoas, deixando claro que só poderá afirmar progresso na educação inclusiva quando ocorrerem adequações de currículos, métodos, técnicas, recursos educativos e organizações específicas para atender as necessidades das pessoas com deficiência intelectual na educação brasileira, que esteja focada em competências e habilidades que tenham condições de transcender os limites meramente familiares, tornando-os verdadeiros cidadãos brasileiros.

Por fim, foi possível vislumbrar que o Brasil já deu seus primeiros passos em direção da inclusão social e do pleno desenvolvimento humano das pessoas com Síndrome de Down, porém, muito deve ser feito ainda para que especialmente o direito à educação não se restrinja apenas aos textos normativos, mas que ocorra de modo efetivo na sociedade, bem como que os entes estatais cumpram seu papel institucional de garanti-los e de fiscalizar o seu devido cumprimento.

\section{REFERÊNCIAS}

AMERICAN PSYCHIATRIC ASSOCIATION. Diagnostic and statistical manual of mental disorders. 4. ed. Washington, DC, 1995.

ARAUJO, Luiz Alberto David. A Proteção Constitucional das Pessoas Portadoras de Deficiência. Brasília: Coordenação Nacional para a Integração da Pessoa Portadora de Deficiência, 1994.

ARAUJO, Luiz Alberto David; MAIA, Maurício. O Conceito de Pessoas com Deficiência e algumas de suas Implicações no Direito Brasileiro. Revista de Direito Constitucional e Internacional. vol. 86, Jan./2014.

BOBBIO, Norberto. A era dos direitos. Rio de Janeiro, Campus, 1992.

BRASIL. Constituição Federal (1988). São Paulo: Saraiva, 2019.

BRASIL. Ministério da Justiça / Secretaria dos Direitos da Cidadania/ Coordenadoria Nacional para Integração da Pessoa Portadora de Deficiência - Corde. Normas e recomendações internacionais sobre deficiências. Brasília, 1997.

BRASIL. Programa de ação mundial para as pessoas com deficiência. Brasília, 1997.

BRASIL. Os direitos das pessoas portadoras de deficiência. Brasília, Coordenadoria Nacional para Integração da Pessoa Portadora de Deficiência - Corde, 1996.

BRASIL. MINISTÉRIO DA EDUCAÇÃO E CULTURA (MEC). Salto Para o Futuro:

Educação Especial. Tendências Atuais. Série de Estudos. Educação a distância, Brasília, 1999.

BRASIL. Decreto n. 6.949, de 25 de agosto de 2009. Promulga a Convenção Internacional sobre os Direitos das Pessoas com Deficiência e seu Protocolo Facultativo, assinados em Nova York, em 30 de março de 2007. Disponível em: <http://www.planalto.gov.br/ccivil_03/_ato20072010/2009/decreto/d6949.htm>. Acesso em: 20 nov. 2019.

CARVALHO, R. E. Temas em educação especial. Rio de Janeiro: Casa da Palavra, 1997. 
FÁVERO, Eugênia A.G. Direitos das pessoas com deficiência: garantia de igualdade na diversidade. Rio de Janeiro: WVA Editora; 2004.

FEDERAÇÂO BRASILEIRA DAS ASSOCIAÇÔES DE SÏNDROME DE DOWN. Perfil das percepções sobre as pessoas com síndrome de Down e do seu atendimento: aspectos qualitativos e quantitativos. Brasília, 1999.

MARTIN, Andréia Garcia; MARTA, Tais Nader. O Dever Estatal de Garantir o Treinamento de Cães-Guia - O Direito à Acessibilidade das Pessoas com Deficiência Visual e sua Tutela Jurisdicional In: Direitos Fundamentais \& Justiça, n. 13 - out./dez. 2010. Disponível em: http://www.dfj.inf.br/Arquivos/PDF_Livre/13_Dout_Nacional_9.pdf. Acesso em: 02 dez. 2019.

MEZZAROBA, Orides; MONTEIRO, Cláudia Servilha. Manual de Metodologia da Pesquisa no Direito. São Paulo: Saraiva 2016.

ORGANIZAÇÃO MUNDIAL DE SAÚDE. Declaração de Montreal sobre a Deficiência Intelectual. 2004.

ONU. UNESCO - Organização das Nações Unidas para a Educação, Ciência e Cultura / Ministério da Educação e Ciência da Espanha / Coordenadoria Nacional para Integração da Pessoa Portadora de Deficiência - Corde. Declaração de Salamanca e linha de ação sobre necessidades educativas especiais. Brasília, 1994.

PENA, Gil. Deficiência intelectual e a Síndrome de Down: A deficiência intelectual em indivíduos com Síndrome de Down é consequência de privação cultural, não uma determinação genética, Comdef, Rio de Janeiro, 2009.

SASSAKI, Romeu Kazumi. Atualizações Semânticas na inclusão de pessoas: deficiência mental ou intelectual? Revista Nacional de Reabilitação, ano IX, n. 43, mar./abr. 2005.

SASSAKI, Romeu Kazumi. Por falar em Classificação de Deficiências. Revista Brasileira de Tradução Visual, Pernambuco, vol. 12, n. 12, 2012, p. 02. Disponível em: http://www.rbtv. associadosdainclusao.com.br/index.php/principal/article/view/157/265. Acesso em: 04 dez. 2019.

SMITH, J. D. The myth of mental retardation: paradigm shifts, disaggregation, and developmental disabilities. Mental Retardation, 40, 2002.

TEPERINO, Maria Paula. Comentários à Legislação Federal Aplicável às Pessoas

Portadoras de Deficiência. Rio de janeiro: Editora Forense, 2001.

VOIVODIC, Maria Antonieta. Inclusão escolar de crianças com síndrome de Down. 6. Ed. Rio de Janeiro: Vozes, 2011.

WERNECK, Cláudia. Ninguém mais vai ser bonzinho na sociedade inclusiva. Rio de Janeiro: WVA, 1997.

Recebido em: 23/10/2019.

Aprovado em: 23/12/2019. 